\title{
Pathways and variability of the off-equatorial undercurrents in the Atlantic Ocean
}

\author{
Sabine Hüttl-Kabus ${ }^{1}$ and Claus W. Böning ${ }^{2}$ \\ Received 17 December 2007; revised 13 June 2008; accepted 16 July 2008; published 22 October 2008.
}

[1] The cold upwelling waters of the eastern tropical oceans not only interact with the atmospheric circulation via changing the sea surface temperatures but also influence the biological activity via affecting the nutrient and oxygen contents of the upwelling waters. While the sources of the equatorial upwelling associated with the Equatorial Undercurrent (EUC) have been studied extensively, the relevance of the northern and southern off-equatorial undercurrents (NEUC, SEUC) for the off-equatorial upwelling regions has remained unclear. In this study we use output from a highresolution, $1 / 12^{\circ}$ model (FLAME) to investigate the mean pathways and variability of the off-equatorial undercurrents (OEUCs) in the Atlantic. In particular, a calculation of Lagrangian trajectories helps to gain insight into the source waters of the OEUCs and their connection to the upwelling regions in the eastern tropical Atlantic. In the model solution the sources of both OEUCs belong almost exclusively to the Southern Hemisphere. The pathways of the source waters are found to be governed by strong recirculations between the different eastward and westward zonal currents because of intense eddy motions associated with the tropical instability wave activity. Whereas the SEUC is predominantly fed through the recirculation in the ocean interior, the NEUC is also fed by a weak inflow from the western boundary current. Investigation of the fate of the NEUC shows only a weak direct supply to the upwelling in the Guinea Dome and along the African coast but a significant contribution to the equatorial upwelling.

Citation: Hüttl-Kabus, S., and C. W. Böning (2008), Pathways and variability of the off-equatorial undercurrents in the Atlantic Ocean, J. Geophys. Res., 113, C10018, doi:10.1029/2007JC004700.

\section{Introduction}

[2] The upwelling regions of the eastern tropical oceans are areas of strong interaction between different components of the climate system. The cold upwelling waters not only influence the heat contents of the atmosphere and ocean but are also essential for the marine biological activity by providing recently ventilated waters, enriched in oxygen and nutrients. Upwelling regions in the Atlantic are found along the equator, off northwest Africa in the Guinea Dome and off the coast of Mauritania as well as off southwest Africa in the Angola Gyre/Dome. The upwelling regions are supplied by waters from the subtropics as revealed by examinations of salinities [Metcalf and Stalcup, 1967] and tracers [Tsuchiya, 1986] in the tropical Atlantic. The transfer of subtropical waters into the equatorial regime can be understood in terms of the shallow subtropical cells (STCs) which involve geostrophic flows in the thermocline toward the equator where the waters reach the surface (upwelling) and flow back to the subtropics via surface Ekman transport [McCreary and Lu, 1994].

\footnotetext{
${ }^{1}$ Institut für Umweltphysik, Universität Bremen, Bremen, Germany.

${ }^{2}$ Leibniz-Institut für Meereswissenschaften an der Universität Kiel, Kiel, Germany.

Copyright 2008 by the American Geophysical Union. 0148-0227/08/2007JC004700\$09.00
}

[3] For the Atlantic Ocean an asymmetry of the source regions for the upwelling waters has been observed, manifested in a prevailing southern hemispheric origin of the water masses. Modeling results related this asymmetric behavior to the existence of the northward conveyer belt return flow which is found to block a northern hemispheric subtropical-tropical water mass exchange [Fratantoni et al., 2000; Jochum and Malanotte-Rizzoli, 2001].

[4] The detailed water mass pathways toward the upwelling regions are complicated by the equatorial system of zonal currents flowing alternately eastward and westward between $10^{\circ} \mathrm{N}$ and approximately $6^{\circ} \mathrm{S}$. The Equatorial Undercurrent (EUC), flowing eastward along the equator, is the most investigated of the equatorial zonal currents and regarded to be the main upwelling branch of the STC [Tsuchiya, 1986]. Modeling studies by Philander and Pacanowski [1986] revealed a direct link between the EUC variability, the thermocline depth and the strength of the zonal wind stress and elucidated the main physical mechanisms creating variability of the undercurrent. The connection of the EUC transports and the corresponding upwelling variability in the eastern tropical Atlantic has been extensively discussed by Hormann and Brandt [2007] by using the same high-resolution ocean model output that is used in this study.

[5] As a source of the off-equatorial upwelling regions in the tropical Atlantic the eastward flows centered around 
$4^{\circ} \mathrm{N} / \mathrm{S}$ (the North/South Equatorial Undercurrent (NEUC/ SEUC)) are under discussion. An assumption of such a link between the Guinea Dome $\left(8^{\circ} \mathrm{N}-14^{\circ} \mathrm{N}, 28^{\circ} \mathrm{W}-20^{\circ} \mathrm{W}\right)$ and the NEUC as well as between the Angola Gyre $\left(5^{\circ} \mathrm{S}-15^{\circ} \mathrm{S}\right.$, $5^{\circ} \mathrm{W}-5^{\circ} \mathrm{E}$ ) and the SEUC was first suggested by Voituriez [1981] relying on analogies between the tropical eastern Atlantic and the eastern equatorial Pacific, for which a connection to the off-equatorial undercurrents (OEUCs) was suggested by water mass analyses [Tsuchiya, 1975]. A recent modeling study of the Angola Dome and its variability by Doi et al. [2007] suggests a connection between the SEUC and the northern Angola Dome, which is also supported by observations of Mercier et al. [2003]. However, observational evidence of the fate of the undercurrents and their links to the doming regions is still sparse for both oceans, despite the much improved documentation of the NEUC and SEUC by recent current meter sections taken between $23^{\circ} \mathrm{W}$ and $29^{\circ} \mathrm{W}$ [Brandt et al., 2006], and $10^{\circ} \mathrm{W}$ and $5^{\circ} \mathrm{E}$ [Bourlés et al., 2002].

[6] Understanding of the dynamics and pathways of the subtropical-tropical exchange is complicated by the small meridional scales and strong intraseasonal variability of the OEUCs. A particular source of the variability are the tropical instability waves (TIWs) generated mainly by the meridional shear between the narrow zonal currents; however, there are indications that also baroclinic instabilities contribute to the generation of the TIWs [Grodsky et al., 2005; Jochum et al., 2004a]. The TIWs occur mainly in the summer months, are confined to the central and western tropical Atlantic with periods between 30 and 60 days. The waves represent a strong signal in equatorial current records and play an important role in the equatorial heat budget [Grodsky et al., 2005].

[7] Several theories of the dynamics of the OEUCs have been proposed but a theory explaining most of the observed features of the undercurrents is still lacking. The first attempts to explain the formation of the currents were linear theories by McPhaden [1984] and McCreary [1981] suggesting the OEUCs to be meridional lobes of the equatorial undercurrent, sustained by a balance between vertical diffusion of relative vorticity and advection of planetary vorticity. In some contradiction to these theories, observational studies in the Pacific [Johnson and McPhaden, 1999; Rowe et al., 2000] and Atlantic [Bourlés et al., 2002] revealed the OEUCs to form separate current cores and to diverge poleward on their way to the east. This divergence phenomenon is related to the eastward shoaling of the equatorial thermocline and the conservation of potential vorticity [Johnson and Moore, 1997].

[8] Another approach to understand the dynamics of the OEUCs was given by Marin et al. [2000, 2003] and Hua et al. [2003]. Marin et al. [2000] point out the similarities between the equatorial oceanic zonal current system and the atmospheric Hadley cell, suggesting analogies in their dynamics, i.e., a key role of conservation of angular momentum. However, while the atmospheric cells are driven by releasing latent heat during convection a corresponding diapycnal process driving the oceanic cells has not been identified yet.

[9] A possible mechanism for the diapycnal transfer was proposed in a model study by Jochum et al. [2004b]. They find the meridional heat flux induced by the instability waves affecting the meridional slope of the isopycnals and thus generating the OEUC flow. Another possible diapycnal transfer process would be provided by a connection of the OEUCs to the upwelling. McCreary et al. [2002] and Furue et al. [2007] propose that the OEUCs could be drawn by the off-equatorial upwelling in the doming regions, implying the undercurrents to be important as source waters for this upwelling and the model study by Doi et al. [2007] supports this idea.

[10] The present study addresses the questions of the pathways and variability of the OEUCs by examining the results of a high-resolution model $\left(1 / 12^{\circ}\right)$ experiment. The paper is organized as follows: section 2 introduces the model and provides the background for the trajectory analysis. Section 3 provides a description of the mean flow characteristics and its variability patterns. The pathways of the OEUCs are then examined in section 4 using a variety of Lagrangian particle ensembles. A summary and discussion is given in section 5 .

\section{Model and Methods}

\subsection{Model Configuration}

[11] This study builds on a simulation using a highresolution $\left(1 / 12^{\circ}\right)$ version of the FLAME model (Family of Linked Atlantic Ocean Model Experiments). The $\mathrm{z}$ coordinate model is based on a modified version of the Modular Ocean Model (MOM2) [Pacanowski, 1995]. The simulation covers the North Atlantic between $70^{\circ} \mathrm{N}-18^{\circ} \mathrm{S}$, $100^{\circ} \mathrm{W}-16^{\circ} \mathrm{E}$ and uses 45 levels in the vertical, with a $10 \mathrm{~m}$ resolution at the surface, smoothly increasing to a maximum of $250 \mathrm{~m}$ below $2250 \mathrm{~m}$. Vertical mixing is parameterized based on a stability-dependent scheme for vertical diffusivity $\left(\mathrm{k}_{h}=0.1-4.0 \mathrm{~cm}^{2} / \mathrm{s}\right)$ and viscosity $\left(\mathrm{k}_{m}=2.0-10.0 \mathrm{~cm}^{2} / \mathrm{s}\right)$ as described in more detail by Böning and Kröger [2005], and a KT scheme [Kraus and Turner, 1967] for the mixed layer. The model uses biharmonic friction and Laplacian isopycnal diffusion, the values for diffusivity and viscosity are $50 \mathrm{~m}^{2} / \mathrm{s}$ and $2 \times 10^{10} \mathrm{~m}^{4} / \mathrm{s}$.

[12] The 10-year spin-up of the model starts from a climatology based on a combination of Levitus and Boyer [1994] and Boyer and Levitus [1997] and uses the climatological monthly mean wind stress and heat flux forcing derived from the ECMWF analyses by Barnier et al. [1995]. The spin-up is followed by an interannually forced run using NCEP/NCAR reanalysis products [Kalnay et al., 1996] from 1987-2003. The formulation of the surface heat flux follows Barnier et al. [1995] and Eden and Willebrand [2001]. The northern and southern boundaries are open boundaries with climatological (combined [Levitus and Boyer, 1994; Boyer and Levitus, 1997]) inflow conditions for temperature and salinity and vertically integrated transports from an Arctic model [Brauch and Gerdes, 2005] at the northern boundary. The southern boundary condition is calculated from the Sverdrup relation and the combined Levitus climatology.

\subsection{Model Output and Definitions}

[13] The present model analysis bases on data of two runs of the $1 / 12^{\circ}$ model. For calculation of the mean currents and their variability monthly mean data of the interannual run for the years 1987-2003 is used. To investigate the effect of 
high-frequency variability we analyze three-daily output available for the 1997-1999 year period additionally. The trajectory calculations base on daily output fields of the last year of the climatological spin-up (year 10). This climatological year is representative for the mean circulation when comparing to the 15-year mean of the interannual run and has been used before in the study by Getzlaff et al. [2006].

[14] The transports of the eastward zonal currents in the equatorial region are calculated by using a combination of latitudinal and density boundaries, based on Figure 1a: the Equatorial Undercurrent (EUC) transport is calculated as the eastward transport between $2.5^{\circ} \mathrm{N}$ and $2.5^{\circ} \mathrm{S}$ and $\sigma_{\theta}=24.2$ to 26.8, the transport of the North Equatorial Undercurrent (NEUC) is given by the integration of the eastward velocities between $3^{\circ} \mathrm{N}$ and $6^{\circ} \mathrm{N}$ and $\sigma_{\theta}=25.5$ to 26.8 . The South Equatorial Undercurrent (SEUC) is defined analogous to the northern undercurrent as the eastward transport between $3^{\circ} \mathrm{S}$ and $6^{\circ} \mathrm{S}$ and $\sigma_{\theta}=25.5$ to 26.8. The NECC is defined as the eastward flow above $\sigma_{\theta}=25.5$ between $4^{\circ} \mathrm{N}$ and $10^{\circ} \mathrm{N}$. For the westward currents no transport estimates have been calculated.

\subsection{Trajectory Calculations}

[15] A main part of this work is based on analyses of particle trajectories, admitting a direct investigation of circulation pathways. A trajectory of a particle is calculated from the three-dimensional Eulerian velocity field by integration of the differential equation $d \vec{x} / d t=\vec{v}$, whereby $\vec{x}$ denotes the particles position and $\vec{v}$ the three-dimensional velocity field. This calculation is done offline using velocity output fields stored at monthly or daily time intervals. The offline diagnostic has some advantages compared to online calculations: it allows to perform a variety of particle launches, to average or manipulate the Eulerian velocity fields (e.g., for exploring the effects of eddying motions), and to integrate trajectories both forward and backward in time to study the source waters and the fate of a current.

[16] The trajectories are started along specific sections of interest, i.e., for the NEUC at the $23^{\circ} \mathrm{W}$ section and for the SEUC along the $10^{\circ} \mathrm{W}$ section. Floats were seeded 4 times a year: at 15th of February, May, August, and November. Sensitivity runs with floats starting at more and slightly different times a year did not reveal significant differences in the trajectory distributions. At the start, sections the floats are distributed in a transport-weighted manner with each float being proportional to a fraction of the total transport through the section, following ideas outlined by Blanke et al. [1999]. The method forces a high number of floats in regions with high transports whereas in regions with weak flow only a smaller number is used to represent the current. Note, that we use the method of Blanke et al. [1999] only for the distribution of the floats, and not for calculating transport estimates or stream functions. The reason is that we are mainly interested in eddy-induced pathways in the inner tropics, which involve strong recirculations between the equatorial current bands that is prolonging the residence time in the gyre. Calculating stream functions as defined by Blanke et al. [1999] would thus require trajectory integrations over extremely long periods to allow for all floats to leave the recirculation gyre; this eddy-related recirculation would not be apparent in such a stream function. An analogous argument can be applied for the calculation of
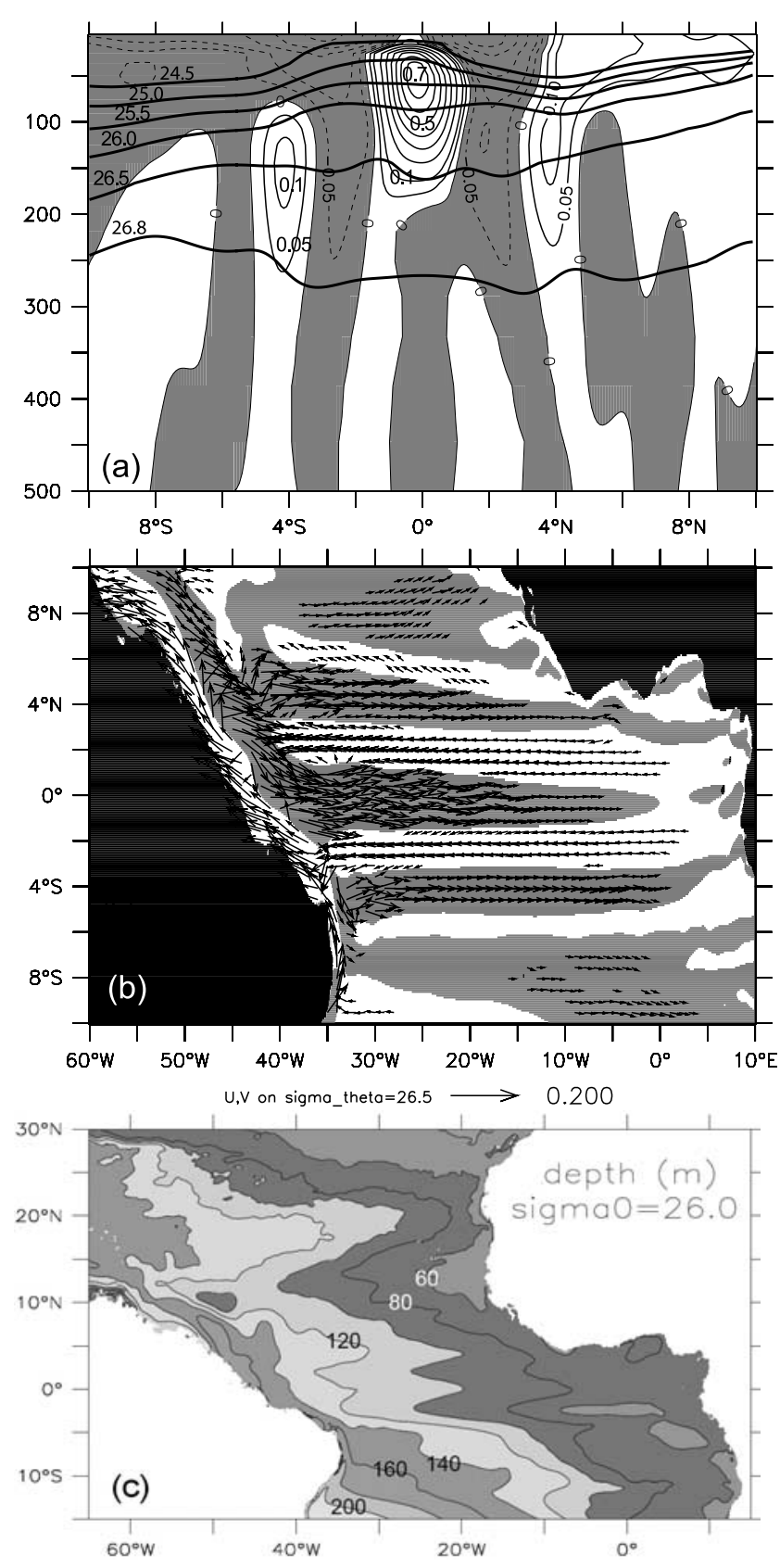

Figure 1. Annual mean of the equatorial circulation in the FLAME- $1 / 12^{\circ}$ model: (a) section of zonal velocity at $23^{\circ} \mathrm{W}$, (b) horizontal velocity on the on the isopycnal surface $\sigma_{\theta}=$ 26.5, representing the core of the SEUC and NEUC and (c) depth of $\sigma_{\theta}$ giving an indication of the doming regions in the eastern tropical basin. Every sixth vector in meridional and every twelfth vector in zonal direction are shown.

transports along a section which is strongly influenced by eddy variability. However, for a discussion of the pathways there is no need to extend the calculation of the trajectories in a high temporal and spatial resolution for more than a few years, as we will discuss by comparing integration periods of 4 to 15 years.

[17] For each of the Lagrangian investigations around 50000 floats were seeded. To get an integral view of the sources and fate of the currents, we first bin the transports at 
each time step on a $1 / 10^{\circ}$ grid and sum them up in depth and time. This gives a float distribution map, indicating the preferred pathways of the trajectories. From this distribution maps we will argue that the net transports across the edges of zonally elongated boxes can be used to describe the pathways more quantitatively. The resulting time series for each of the boxes can be used to track the pathways of the OEUC waters through the different equatorial current bands.

\section{Eulerian Characteristics of the Tropical Atlantic Circulation}

\subsection{Mean State}

[18] It is useful to precede the discussion of variability by an examination of the mean current patterns comprising the subtropical-tropical current regime and to relate the ocean model output to results obtained from observations. Figure 1a depicts the mean flow for a zonal section at $23^{\circ} \mathrm{W}$ across the equator, and Figure $1 \mathrm{~b}$ depicts the currents on the 26.5 isopycnal representing the core of both the Northern and Southern Equatorial Undercurrents. Figures $1 \mathrm{a}$ and $1 \mathrm{~b}$ reveal a strong eastward equatorial undercurrent (EUC) at depths between 20 and $250 \mathrm{~m}$, apparently fed primarily by the retroflection of the western boundary current, the North Brazil (Under)current (NBC). The NBC is visible as the Western Boundary Current, partly fed by the South Equatorial Current (SEC) south of $6^{\circ} \mathrm{S}$, a result in good accordance with observations of Schott et al. [2005]. Between about $5^{\circ} \mathrm{N}$ and $10^{\circ} \mathrm{N}$ the NBC retroflects equatorward but is heavily obscured in the long-term mean field due to the strong seasonal and intraseasonal variability in this regime. A detailed analysis of these patterns for the FLAME model is given by Böning and Kröger [2005] and Stramma et al. [2005]. Away from the western boundary different zonal current bands are observable: flanking the EUC are the two westward branches of the SEC on each side of the equator, poleward of which eastward currents occur, centered around $4^{\circ}$ latitude. The South Equatorial Undercurrent (SEUC) emerges as a coherent eastward current east of $\sim 28^{\circ} \mathrm{W}$, between the western boundary and $\sim 28^{\circ} \mathrm{W}$ the circulation is disturbed by some eddy or wave patten, which will be discussed in more detail in section 3.2. The North Equatorial Undercurrent (NEUC) indicates a connection with the western boundary and is difficult to separate from the shallower core of the North Equatorial Countercurrent (NECC) most of the year. Seasonally, a second NECC core develops around $8^{\circ} \mathrm{N}$ visible as the northernmost current band visible in Figure 1b; this two-core structure nearly vanishes in the long-term (see Figure 1a). The isopycnal $\sigma_{\theta}=25.5$ is chosen as the density boundary to separate the current cores of the NECC and NEUC (visible most clearly in the summer season, but not shown here).

[19] The current cores of the OEUCs exhibit similar depth and density ranges on both sides of the equator: covering depths between 80 and $300 \mathrm{~m}$ and densities of $\sigma_{\theta}=25.5-$ 26.8 (see Figure 1a), they form the poleward boundaries of the equatorial thermostat, a region of nearly uniform water mass bodies in terms of temperature and salinity. The core depths and densities of the OEUCs, however, are slightly different: the SEUC core is situated around 120-200 m with a core density of $\sigma_{\theta}=26.5$, the NEUC core lies slightly shallower (100-180 m) with lower core densities around $\sigma_{\theta}=26.2$. An analogous behavior was reported in the observations during July 1999 at $23^{\circ} \mathrm{W}$ by Bourlés et al. [2002]. The more recent occupation of the $23^{\circ} \mathrm{W}$ section by Brandt et al. [2006] shows no clear signature of the NEUC between $3^{\circ} \mathrm{N}$ and $5^{\circ} \mathrm{N}$ in the mean; however, this may be attributed to the fact that most observations have been carried out south of the equator (see Brandt et al. [2006] for a description). The maximum eastward mean current velocity of is about $10 \mathrm{~cm} / \mathrm{s}$ for both undercurrents and is slightly smaller than for the observed currents (SEUC, $15 \mathrm{~cm} / \mathrm{s}$ [Brandt et al., 2006]; NEUC, $20 \mathrm{~cm} / \mathrm{s}$ [Bourlés et $a l ., 2002]$ ). The mean mass transports of the OEUCs (for definition of the current transports, see section 2) across $23^{\circ} \mathrm{W}$ in the model are $2.4 \mathrm{~Sv}\left(1 \mathrm{~Sv}=10^{6} \mathrm{~m}^{3} / \mathrm{s}\right)$ for the NEUC and 2.6 Sv for the SEUC. Observed mean transports have been difficult to obtain because observations in the regions off the equator are sparse, especially prior to 2001. Brandt et al. [2006] estimated an eastward SEUC transport of 4.8 $\mathrm{Sv}$ above $\sigma_{\theta}=26.8$ and $2.2 \mathrm{~Sv}$ below this isopycnal from their measurements.

[20] Voituriez [1981] related the OEUCs to the thermal domes in the eastern part of the basin. However, such a connection is not obvious from the mean circulation in Figure $1 \mathrm{~b}$, the velocities decrease strongly east of $5^{\circ} \mathrm{W}$ (NEUC) and $0^{\circ} \mathrm{W}$ (SEUC). To check if the dome regions are present in the model simulation, the depth of the isopycnal $\sigma_{\theta}=26.0$, which represents the upper parts of both OEUCs, is plotted in Figure 1c. The depth structure of this isopycnal reveals a flattening of the isopycnals near $10^{\circ} \mathrm{N}-18^{\circ} \mathrm{N}$, $30^{\circ} \mathrm{W}-20^{\circ} \mathrm{W}$ which can be partly attributed to the coastal upwelling and the eastern part of the Guinea Dome as well as a shoaling farther north off Mauritania. The models Guinea Dome is rather weak developed and has been investigated in detail by a study of Stramma et al. [2005]. The model's dome is located between $8^{\circ}-14^{\circ} \mathrm{N}$ and between $28^{\circ} \mathrm{W}$ and $20^{\circ} \mathrm{W}$. Additionally, a strong shoaling along the EUC and in the vicinity of the southern model boundary is found. While the northern doming corresponds well to the observed position of the Guinea Dome, the southern upwelling spans a broad region along the coast without a circular doming pattern, an attribute possibly related to the southern model boundary at $18^{\circ} \mathrm{S}$. However, there are two doming patches visible which are in good agreement with the findings of the modeling study by Doi et al. [2007]: one centered around $6^{\circ} \mathrm{E}, 5^{\circ} \mathrm{S}$ and a second centered along the African coast from $7^{\circ} \mathrm{S}$ to $15^{\circ} \mathrm{S}$.

\subsection{Seasonal to Interannual Variability}

[21] A depiction of the seasonal cycle of the zonal current system along the isopycnal $\sigma_{\theta}=26.5$ is given in Figure 2 . Strongest variability is visible in the westward flowing SEC bands between $1^{\circ}$ and $3^{\circ}$ latitude on both sides of the equator, with enhanced westward transports in boreal winter and a strong weakening of the westward flow in midbasin during boreal summer. The most interesting point regarding the discussion of sources and pathways of the OEUCs concerns their connection to the western boundary current regime. While the NEUC seems to be clearly connected to the NBC retroflection during boreal summer to winter, the SEUC never shows such a linkage but a strongly disturbed velocity field near the western boundary is visible in all 

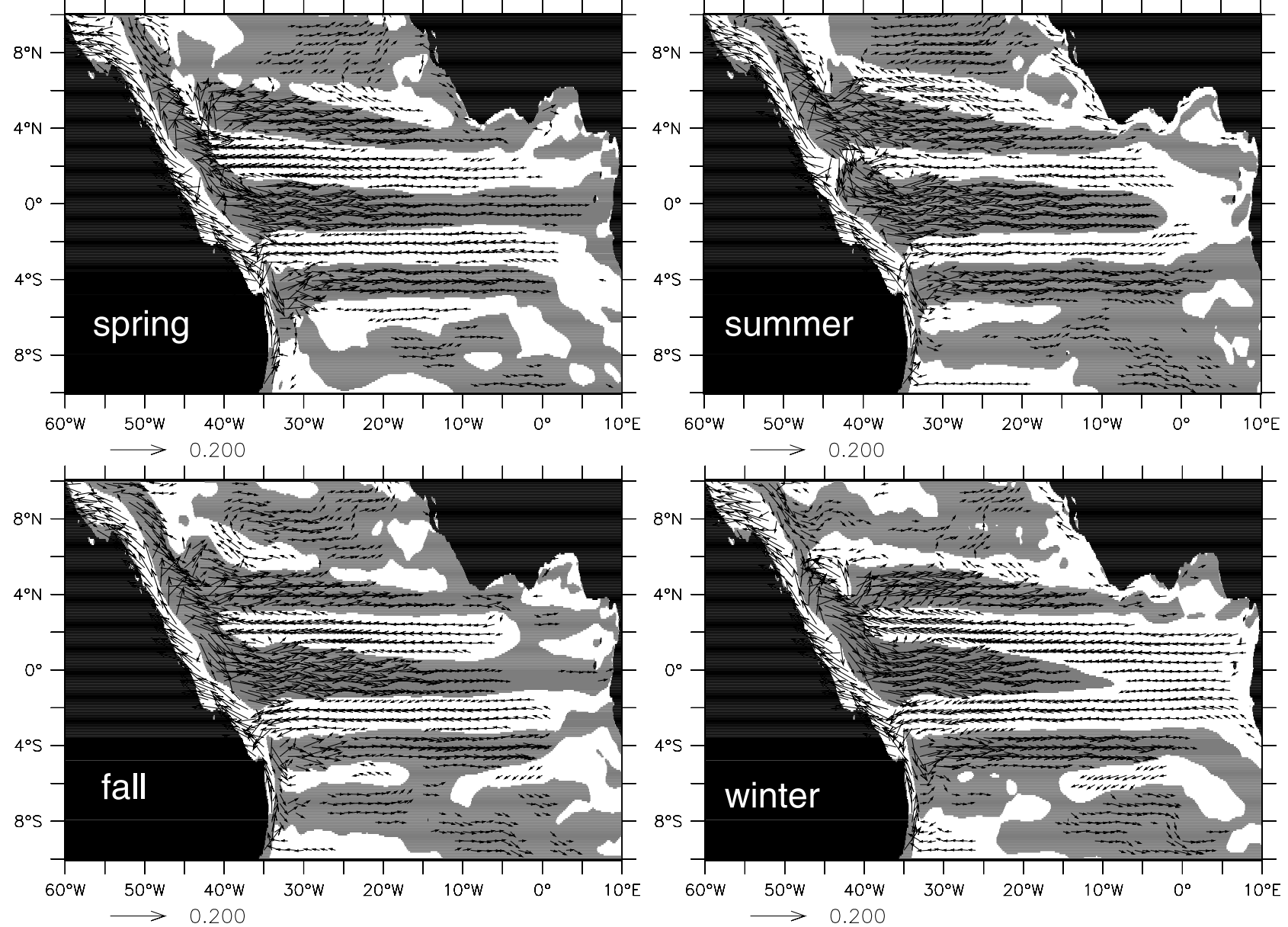

Figure 2. Seasonal cycle of the current field on $\sigma_{\theta}=26.5$, illuminating the variability of the zonal and meridional extents of the equatorial zonal currents trough boreal spring (March, April, May), summer (June, July, August), fall (September, October, November), and winter (December, January, February). The grey scale indicates eastward (grey) or westward (white) flow. Every sixth vector in meridional and every twelfth vector in zonal direction are shown. Vector lengths are limited to $0.2 \mathrm{~m} / \mathrm{s}$.

seasons. To investigate this point, Figure 3 presents the velocity field near the boundary in more detail. In all seasons a strong recirculation pattern is visible. The velocity fields indicate a permanent recirculation of waters from the westward SEC into the western SEUC but never show a flow from the NBC into the SEUC. The recirculation pattern reaches as far as $6^{\circ} \mathrm{S}$ in boreal spring and summer and splits up in smaller eddies during boreal fall and winter. An analogous recirculation pattern is found for the inflow into the NEUC between $2^{\circ} \mathrm{N}$ to $6^{\circ} \mathrm{N}, 41^{\circ} \mathrm{W}$ to $42^{\circ} \mathrm{W}$ during boreal spring and summer (not shown), while during fall and winter the NEUC is fed directly from the NBC retroflection.

[22] In all seasons none of the OEUCs continues toward the eastern boundary: the velocities decrease strongly in the east and the NEUC does not penetrate into the Gulf of Guinea, in good accordance with the results of Elmoussaoui et al. [2005] and Bourlés et al. [2002]. The SEUC cannot be found east of $5^{\circ} \mathrm{E}$. This implies a vertical or horizontal shift of these currents, i.e., upwelling or downwelling or horizontal recirculation. Like in the Pacific, some observations [Bourlés et al., 2002] indicate a poleward shift of the offequatorial undercurrents when flowing eastward, however, the analysis of Mercier et al. [2003] does not show such a divergence for the SEUC but an inflow of the SEUC into the Angola Gyre around $4.5^{\circ} \mathrm{S}, 9^{\circ} \mathrm{W}$. The poleward divergence is not obvious for the model currents, instead, they seem to converge slightly equatorward.

[23] An examination of the time series of the OEUCs, calculated from the models eastward velocities (for details, see section 2), is provided in Figure 4 for two different sections: for the NEUC at $35^{\circ} \mathrm{W}$ and $23^{\circ} \mathrm{W}$ (Figures $4 \mathrm{a}$ and $4 \mathrm{~b}$ ), for the SEUC at $23^{\circ} \mathrm{W}$ and $10^{\circ} \mathrm{W}$ (Figures $4 \mathrm{c}$ and $4 \mathrm{~d}$ ). The amplitude of the annual cycle (dashed line) of the NEUC is about $3 \mathrm{~Sv}$ with maximum transports in June $\left(35^{\circ} \mathrm{W}: 7 \mathrm{~Sv}\right)$ and May $\left(23^{\circ} \mathrm{W}: 4.5 \mathrm{~Sv}\right)$, and minimum transports in October $\left(35^{\circ} \mathrm{W}: 4.2 \mathrm{~Sv}\right)$ and September $\left(23^{\circ} \mathrm{W}\right.$ : 1.2 Sv). The curves indicate a westward phase propagation of the annual signal, consistent with the annual Rossby wave patterns described in the studies of Thierry et al. [2004], Böning and Kröger [2005], and Brandt and Eden [2005].

[24] The interannual variability of the NEUC amounts to a standard deviation of $2 \mathrm{~Sv}$ of the mean annual cycle, i.e., of comparable amplitude to the annual signal (3 Sv) during May to June and November to March $\left(23^{\circ} \mathrm{W}\right)$ and June to 

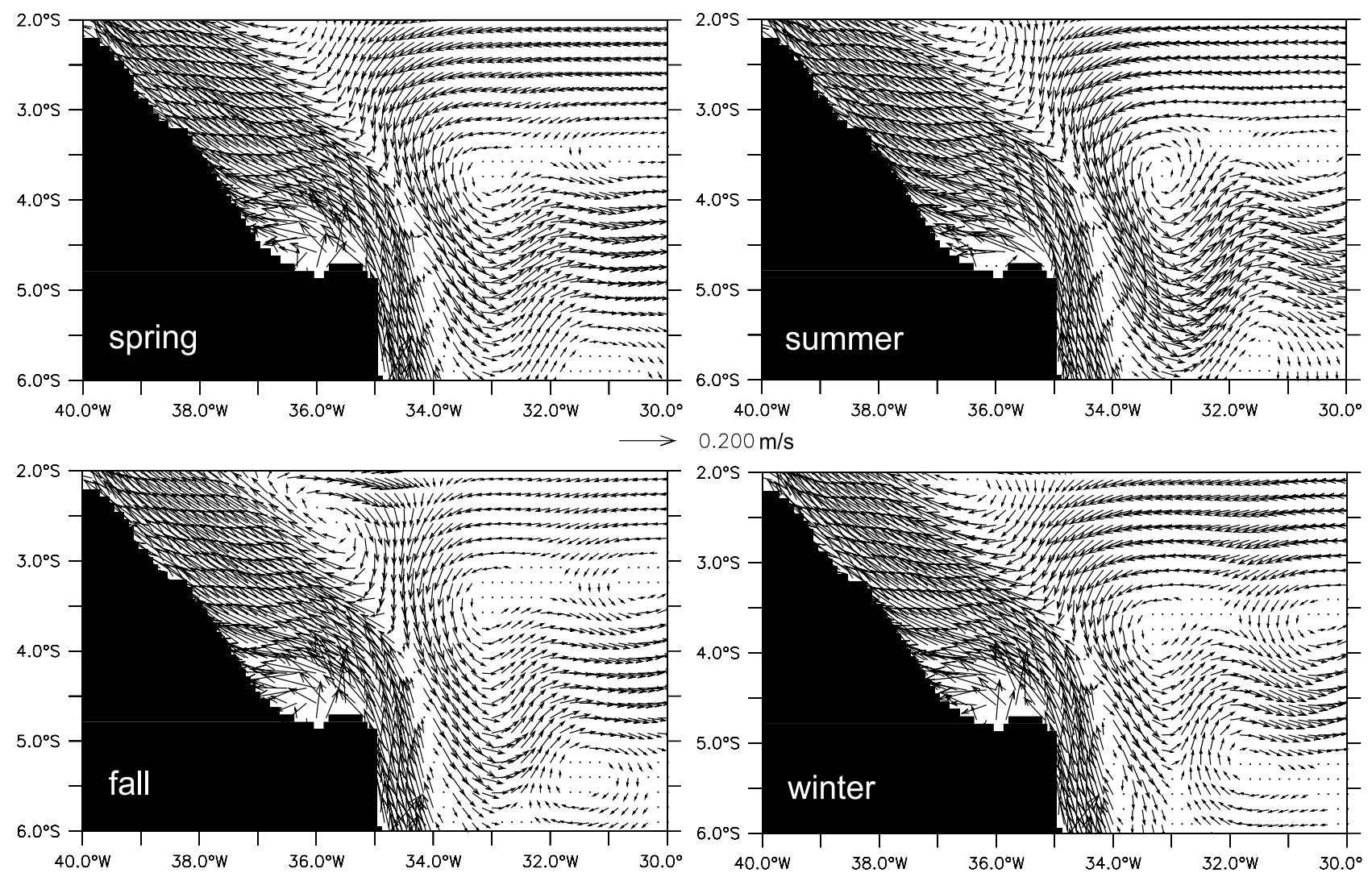

Figure 3. Seasonal cycle of horizontal velocities on the isopycnal surface $\sigma_{\theta}=26.5$ near the western boundary. The SEUC does not show a connection to the NBC for any season. Every second vector is shown. Vector lengths are limited to $0.2 \mathrm{~m} / \mathrm{s}$.

August and October to December $\left(35^{\circ} \mathrm{W}\right)$, respectively but can be understood as a modulation of the annual cycle. Comparison between the monthly mean values and the overlaid three-daily time series for the years 1997-1999 shows the amplitude of the high-frequency variability to be varying strongly from year to year. However, the interannual changes in the western $\left(35^{\circ} \mathrm{W}\right)$ and the central $\left(23^{\circ} \mathrm{W}\right)$ part of the current are not in accordance, i.e., their zonal coherence is limited and cannot be understood as an expression of a zonally propagating wave alone.

[25] The time series of the SEUC at $23^{\circ} \mathrm{W}$ and $10^{\circ} \mathrm{W}$ (Figures $4 \mathrm{c}$ and $4 \mathrm{~d}$ ) suggest a rather different behavior. As for the NEUC, the short-term variability (Figures $4 \mathrm{c}$ and $4 \mathrm{~d}$ ) dominates the interannual fluctuations but these occur yearround and thus do not imply an intensification or reduction of a mean annual cycle. Given the strong fluctuations, a mean annual cycle as calculated from the 15-year time series is of little relevance for the eastward transport of the SEUC. In Figures 4c and 4d the SEUC instead appears as a weak mean current dominated by short-term processes. Because of this stochastic variability it is also problematic to compare the mean model values and the few observational means given by Bourlés et al. [2002] or by Brandt et al. [2006], as these values can differ significantly depending on the length and the members of the average record.

\subsection{High-Frequency Variations}

[26] The high-frequency variability is investigated further by Fourier analysis of the daily velocity fields, using the last year of the model spin-up for the NEUC and SEUC (not shown). Enhanced energy is found particularly in two bands: 30-40 days and 50-60 days. These timescales are in accordance with results from observational records of instability waves [e.g., Weisberg and Weingartner, 1988; Grodsky et al., 2005; Brandt et al., 2006]. Both timescales have been linked to shear instability processes: the 3040 day variability, commonly referred as "tropical instability waves" (TIWs), is linked to the shear instability of the SEC-EUC system [e.g., Qiao and Weisberg, 1998]. The 50-60 day undulations belong to westward propagating eddies slightly north (about $1^{\circ}$ as indicated by Weidman et al. [1999]) of the original instability. These variations have been referred to as "tropical instability vortices" (TIVs) [Foltz et al., 2004] or "Legeckis eddies" [Weidman et al., 1999]. The Fourier decomposition also supports the finding that the annual cycle is the dominating signal for the NEUC. For the SEUC the semiannual component stands out, indicating the presence of a seasonal cycle, which, however, becomes effectively masked by the high-frequency variability as reflected in the time series in Figure 4.

[27] While the equatorial currents in the long-term mean involve only small meridional excursions, strong meridional velocity fluctuations occur associated with the equatorial wave activity. The meridional structure (Figure 5a) of the velocity fields at $23^{\circ} \mathrm{W}$ indicates a nearly equator-symmetric pattern. Strongest amplitudes are found right on the equator and in the latitude bands between $4^{\circ} \mathrm{N} / \mathrm{S}$ and $6^{\circ} \mathrm{N} / \mathrm{S}$. The maximum at the equator is typical for tropical instability 

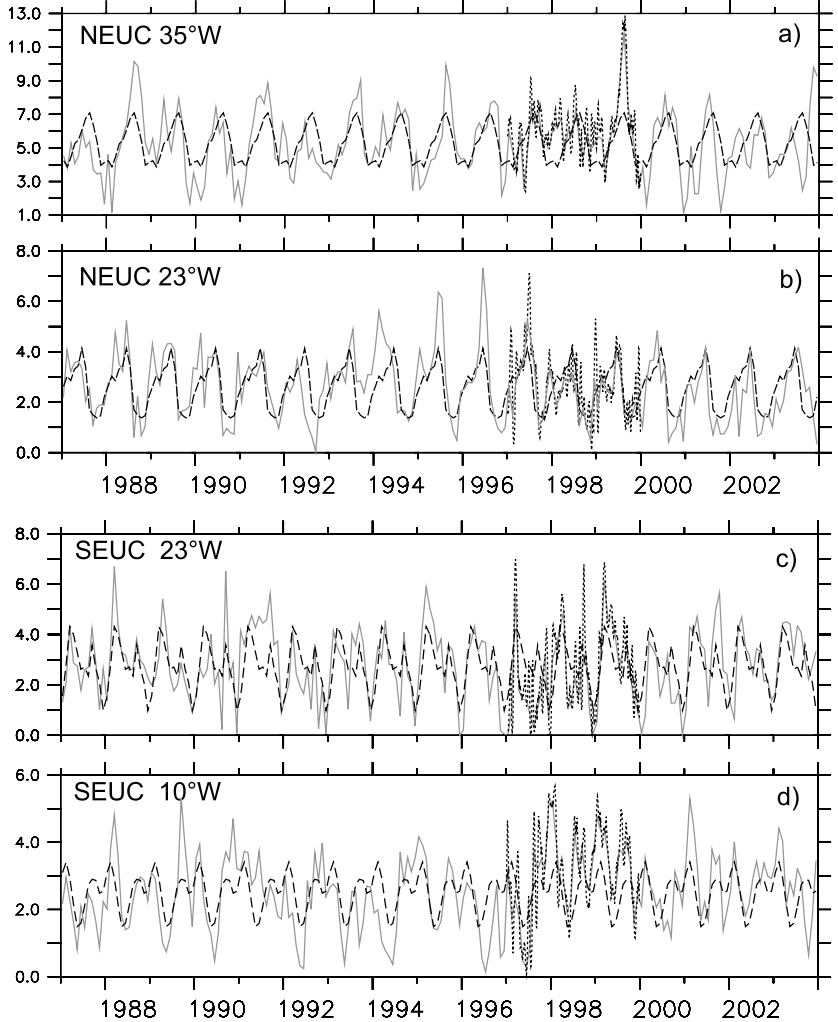

Figure 4. Variability of zonal velocity in the OEUCs from the model run with interannually varying forcing: monthly time series (grey), mean annual cycle (black), and threedaily values for the period 1997-1999 (dotted). (a) NEUC at $35^{\circ} \mathrm{W}$, (b) NEUC at $23^{\circ} \mathrm{W}$, (c) SEUC at $23^{\circ} \mathrm{W}$, (d) SEUC at $10^{\circ} \mathrm{W}$. The interannual variability of both currents is dominated by a modulation of the intraseasonal variability which is almost as large (NEUC) or larger (SEUC) than the mean annual cycle.

waves (TIWs), the maximum off the equator is related to the occurrence of the tropical instability vortices (TIVs). Both instability processes contribute to the anomaly signals of the NEUC and SEUC. Interestingly, the wave and vortex signals do not occur in boreal summer only, but there is a second maximum in boreal winter from October to February. Such a semiannual TIW occurrence has been observed earlier by Weisberg and Weingartner [1988] and is evident in the data discussed by Grodsky et al. [2005] and Brandt et al. [2006]. While the onset of the summer TIWs is nearly as observed, the winter waves in the model occur and vanish earlier by one or two months compared to the observational analysis of Brandt et al. [2006].

[28] The influence of the TIWs and TIVs on the structure of the OEUCs will be investigated further by horizontal snapshots during two events: Figures $5 \mathrm{~b}-5 \mathrm{e}$ show the absolute velocities in $100 \mathrm{~m}$ depth during two summer and two winter months of the years 1998/1999. In both cases the current evolution involves first a meandering of the circulation around $4^{\circ} \mathrm{N} / \mathrm{S}$ (due to TIWs) which breaks up into anticyclonic eddies (the TIVs) during the next days, which propagate toward the western boundary where they end up in the North Brazil Current (NBC). The anticyclones are formed in both hemispheres with similar intensities north and south of the equator. The longitudinal extent of the eddies is about $500 \mathrm{~km}$, in correspondence with the observed vortices of Menkes et al. [2002] and Foltz et al. [2004].

[29] The eddies (or TIVs) emerge in midbasin in both hemispheres, but at slightly different longitudes. In the southern hemisphere the first eddy signatures in summer are visible between $15^{\circ} \mathrm{W}$ and $20^{\circ} \mathrm{W}$ (Figure $5 \mathrm{~b}$ ) which intensify during the westward propagation $\left(20^{\circ} \mathrm{W}-25^{\circ} \mathrm{W}\right.$ in Figure $5 \mathrm{c}$ and $25^{\circ} \mathrm{W}-30^{\circ} \mathrm{W}$ in Figure $5 \mathrm{~d}$ ) and reach the western boundary after 1.5 months (Figure $5 \mathrm{e}$ ). The propagation speed is thus between 40 and $50 \mathrm{~cm} / \mathrm{s}$, which is in the upper range of the observed values from Foltz et al. [2004]. In the northern hemisphere the eddies form west of $20^{\circ} \mathrm{W}$, showing similar propagation properties as their southern counterparts.

[30] Like the TIWs, the eddies also occur in winter. As indicated by Figures $5 f-5 i$, the formation region is shifted about $5^{\circ}$ toward the west, and the southern eddies occur about $2^{\circ}$ farther south. In summary, TIVs are suggested to strongly influence the currents fields of the OEUCs in both seasons and to account for the strong standard deviations from the mean annual cycle noted above. An elucidation of their effect on the pathways of the OEUC waters will be a main concern of the analysis in section 4 .

\section{Pathways in the Equatorial Current System}

[31] In this section the questions of the source waters of the OEUCs, their importance for the eastern tropical upwelling and the impact of the strong eddy variability on the mean pathways in the inner tropics will be studied by using a Lagrangian approach.

\subsection{Sources of the OEUCs}

[32] Results of the trajectory calculation investigating the sources of the NEUC are shown in Figure 6. The trajectories were started along a section at $23^{\circ} \mathrm{W}$ on 15 February, 15 May, 15 August and 15 November and integrated backward in time using the daily velocity fields of the climatological run for 4 years (Figure 6a) and 15 years (Figure $6 \mathrm{~b}$ ). Figures $6 \mathrm{a}$ and $6 \mathrm{~b}$ show the summed pathways of all floats, represented by the number of floats passing the box edges of a $1 / 10^{\circ}$ grid. This gives a trajectory distribution map highlighting the regions with strong recirculations as well as the main pathways of the floats. Figures $6 \mathrm{a}$ and $6 \mathrm{~b}$ reveal the highest concentration of floats along the equatorial zonal currents: the EUC, the northern SEC branch and the NEUC. Between these zonal maxima there are elongated recirculation windows with a smaller float concentration visible: between $35^{\circ} \mathrm{W}-23^{\circ} \mathrm{W}$ and $13^{\circ} \mathrm{W}-3^{\circ} \mathrm{W}$ at the northern flank of the EUC and between $38^{\circ} \mathrm{W}$ and $23^{\circ} \mathrm{W}, 2^{\circ} \mathrm{N}-$ $4^{\circ} \mathrm{N}$. Slightly lower values are visible along the NBC. Figures $6 \mathrm{a}$ and $6 \mathrm{~b}$ show the same pattern of trajectory maxima, the only difference is the higher number of floats which have passed the NBC, the EUC and the recirculation areas. This indicates that the sources of the NEUC are essentially the same as the sources of the EUC, which have been studied in great detail before [Hazeleger et al., 2003], so we will not repeat this here but confine our discussion of the sources of the OEUCs to a discussion of their tropical pathways. Hence, for a discussion of the pathways into the 

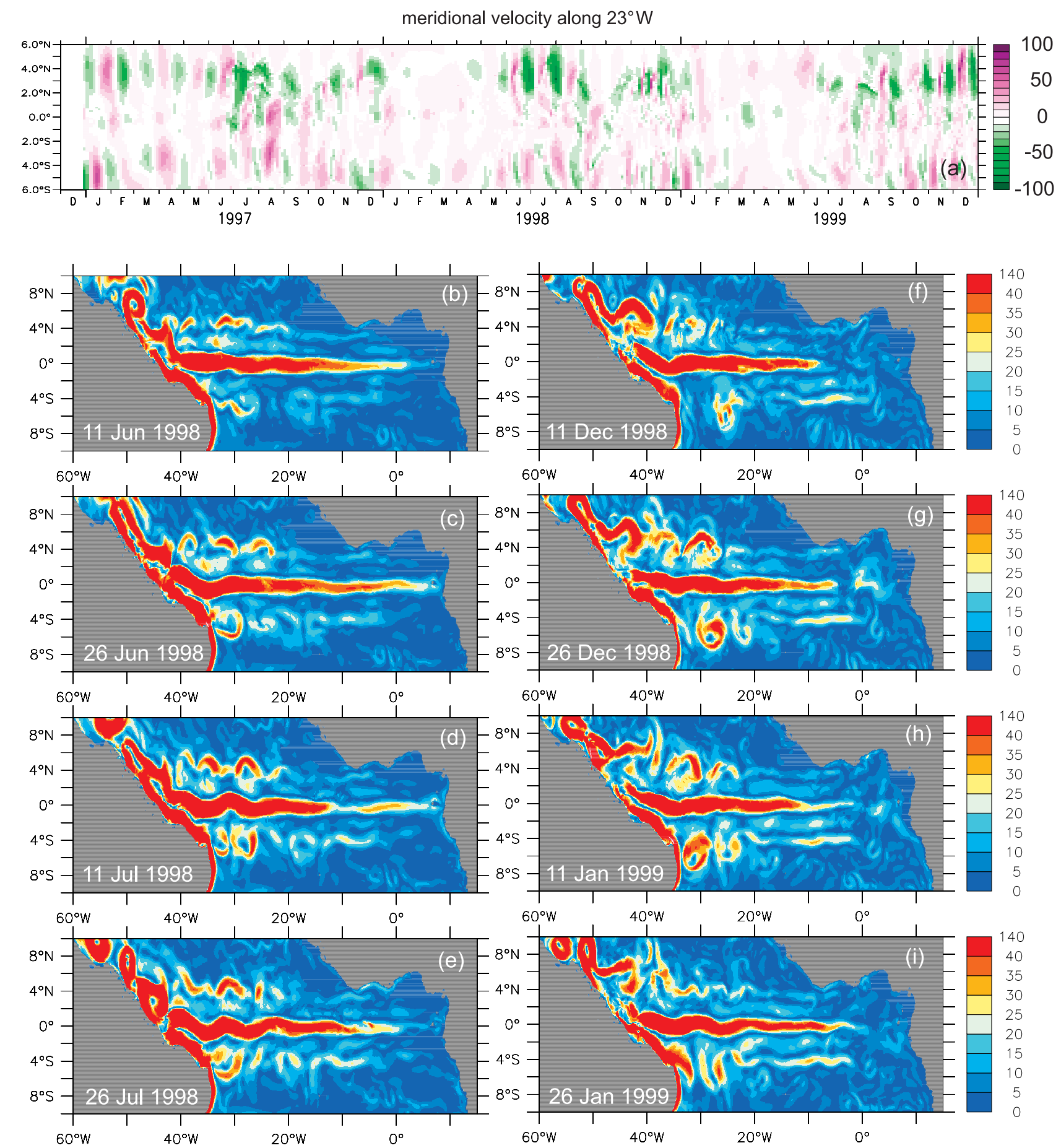

Figure 5. (a) Hovmoeller diagram of the meridional velocity anomaly along $23^{\circ} \mathrm{W}$ in $100 \mathrm{~m}$ depth showing TIWs and TIVs. (b-i) The magnitude of the horizontal current speed at $100 \mathrm{~m}(\mathrm{in} \mathrm{cm} / \mathrm{s})$. Figures $5 \mathrm{~b}-5 \mathrm{e}$ represent the flow field during June-July 1998 and Figures $5 \mathrm{f}-5 \mathrm{i}$ represent the currents during December 1998 to January 1999. The TIWs cause a meandering of the currents, breaking up to eddies (TIVs) in midbasin. The eddies propagate toward the western boundary, on their way mixing properties across the currents.

NEUC (and also the SEUC) the shorter integration time of 4 years is sufficient.

[33] The distribution maps of the floats in Figure 6 suggests two possible pathways of waters into the NEUC: (1) the direct inflow from the NBC into the NEUC and
(2) an inflow from the NBC into the EUC, a deep recirculation into the westward SEC and a second recirculation from the SEC into the NEUC. To investigate the pathways more quantitatively, the boxes introduced in Figure 6b are used to track the trajectories along their way through the 

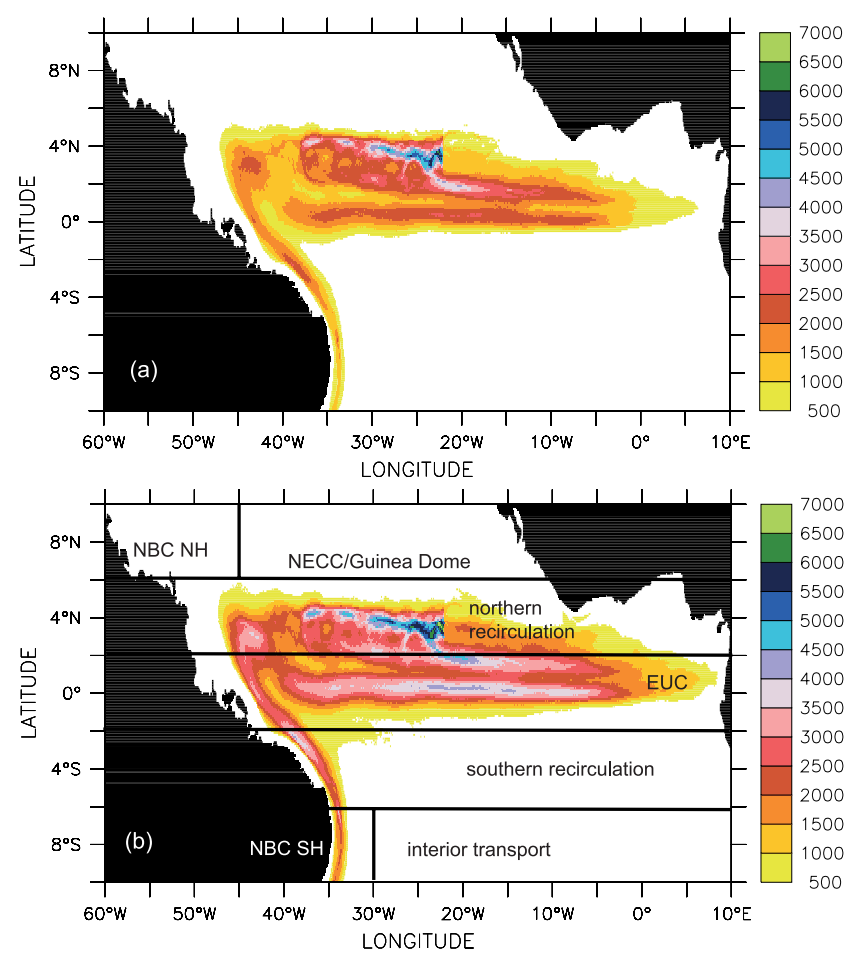

Figure 6. Float distribution maps for the investigation of the NEUC sources. The floats were launched at $23^{\circ} \mathrm{W}$ and integrated backward in time for (a) 4 years and (b) 15 years. The color represents the accumulated float concentration by counting the floats passing the grid lines of a $1 / 10^{\circ}$ grid, independent of depth and time. The main pathways of the floats are visible as regions with high float concentrations. For more details see text. Figure $6 \mathrm{~b}$ also shows the definition of the boxes that will be used for quantification of the trajectory analysis.

different zonal currents. Figure 7a traces the sources of the water by depicting the temporal evolution of the fraction of particles in the boxes defined in Figure 6b, and Figures $7 \mathrm{~b}$ to $7 \mathrm{~d}$ illustrate the behavior by highlighting some specific examples for the different preferred pathways.

[34] The trajectory analysis for the NEUC reveals a surprisingly large part of trajectories to originate from the EUC and the recirculation areas between the EUC and the northern and southern SEC bands. After 4 years of integration only $31 \%$ of the NEUC waters (based on the number of trajectories) are contributed from south of $6^{\circ} \mathrm{S}$, whereas the recirculation fraction (northern and southern recirculation plus EUC) amounts to $66 \%$. After 15 years of integration, around $45 \%$ of the waters originate from south of $6^{\circ} \mathrm{S}$, and $55 \%$ still recirculate between the tropical currents (not shown). So, the fraction of recirculating waters has been decreasing during this time span very slowly only. This supports the idea, that the short integration time of 4 years is long enough to discuss the main water mass pathways. A possible reason for this behavior is that the number of particles reaching the NEUC directly via NBC inflow from the western boundary is low: assuming a mean advection velocity of $0.5 \mathrm{~m} / \mathrm{s}(0.25 \mathrm{~m} / \mathrm{s})$ along the NBC/NEUC, a particle following the current cores would need only between approximately 100 (200) days to pass the distance from the $10^{\circ} \mathrm{S}$ to the NEUC $23^{\circ} \mathrm{W}$ section. However, after 1 year integration only $3 \%$ of the NEUC waters are contributed by trajectories originating from the NBC south of $6^{\circ} \mathrm{S}$. Why only such a low fraction of NBC waters directly enters the NEUC is illustrated in Figures $7 \mathrm{~b}$ to $7 \mathrm{~d}$ : most of the particles, upon reaching the equatorial regime, recirculate multiple times between the eastward (NEUC/EUC) and westward currents bands (SEC).

[35] Figure $7 \mathrm{~b}$ exemplifies this behavior for a trajectory followed backward from the velocity core of the NEUC: its pathway is mainly at depths between 120 and $160 \mathrm{~m}$, with only small vertical movements, and the trajectory finally originates from the EUC. The circulation pattern for a shallower NEUC trajectory in Figure 7c illustrates a similar behavior but with a shorter recirculation time between the equatorial current bands and more pronounced vertical excursions during the loops between the EUC and NEUC. Figure $7 \mathrm{~d}$ gives an example for a trajectory which originates from the NBC retroflection but reveals that even this pathway has connections to the EUC and that the sources of the NEUC are also linked to a southern hemispheric equatorial recirculation; this trajectory undergoes multiple vertical movements during its pathway.

[36] The main conclusion regarding the NEUC pathways up to this point is that the NEUC is supplied mainly by the inflow from the EUC associated with a strong recirculation of water masses between the equatorial currents. The source waters of the NEUC are thus the southern hemispheric waters entering the EUC from the NBC. A direct inflow from the NBC as proposed by Voituriez [1981] and depicted in many schematics of the mean circulation is very low $(5 \%)$. The nature of the indirect pathways will be investigated further after the analogous investigation of the SEUC source waters.

[37] The origins of the SEUC waters are plotted in Figure 8. In many aspects the results of Figure 8a resemble the findings from the NEUC analysis: most trajectories show a connection to the EUC and the southern recirculation $(60 \%$ after 4 years), only about $38 \%$ (after 4 years) originate from south of $6^{\circ} \mathrm{S}$. However, in contrast to the NEUC there is no direct inflow from the NBC as already discussed in the discussion of the Eulerian velocity fields in Figure 3. The examples given in Figures $8 b-8 d$ show more or less strong recirculation patterns and reveal horizontal and vertical zig-zag paths into the SEUC. Hence, the sources of the SEUC can also be found in the waters which enter and leave the EUC.

[38] A plausible source for these circuit pathways is the strong intraseasonal variability of the equatorial current fields as represented by the TIWs and the TIVs. However, as the TIWs can be considered as quasi-linear disturbances of the mean flow field, they cannot account for the substantial meridional mass transfer exhibited in the trajectory analysis. A mechanism for the eddy-induced mass transfer could be provided by TIVs which spin off from the westward propagating waves (see Figures $5 \mathrm{~b}-5 \mathrm{i}$ ).

[39] To assess the importance of this high-frequency variability the trajectory calculations were repeated using monthly mean velocity fields, in which the signatures of the instability waves and eddies are significantly reduced. Figure 9 shows the transport fractions across the box boundaries as obtained by analogous particle integrations 

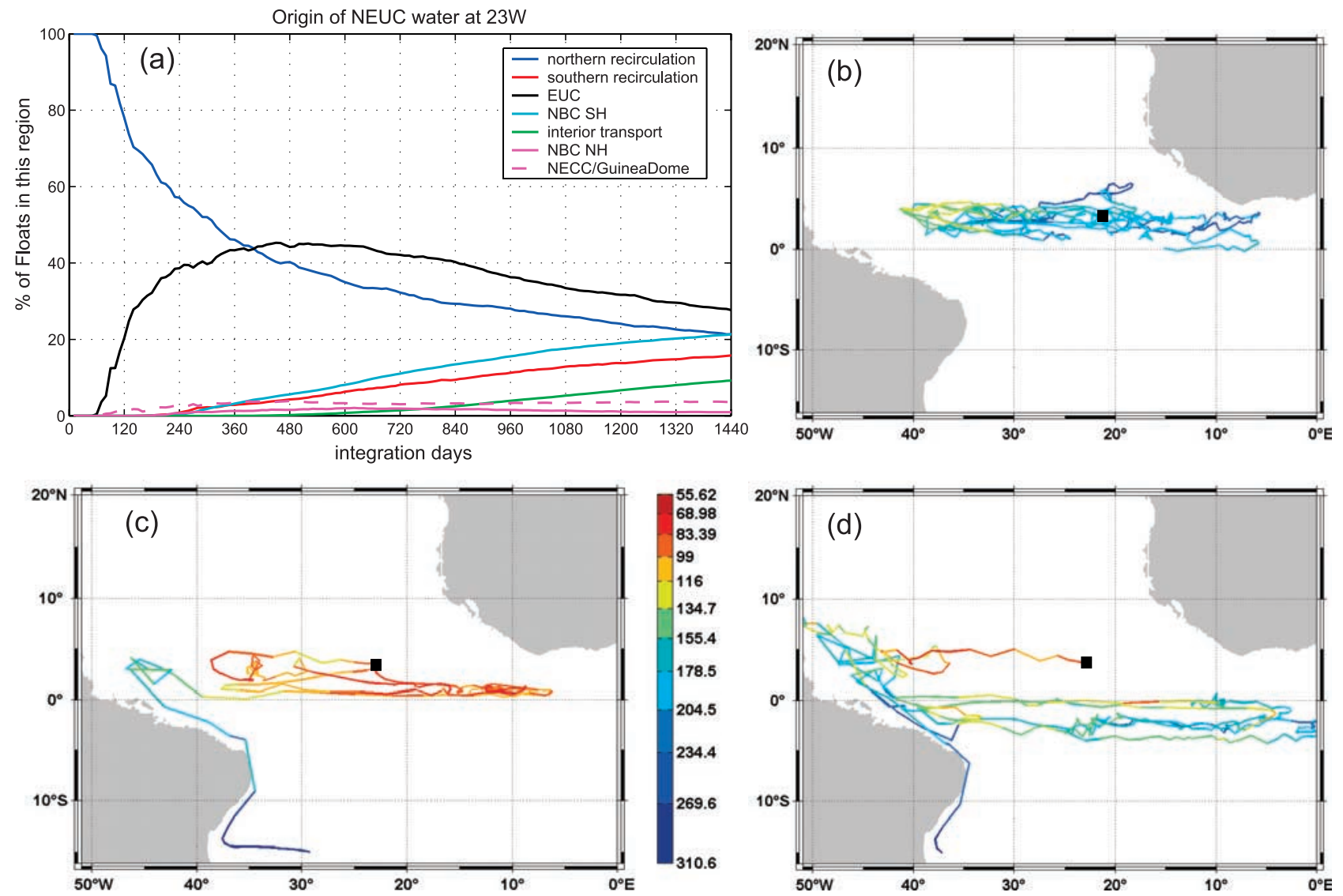

Figure 7. Contributions to the NEUC by different source pathways, based on backward integration of particles launched at $23^{\circ} \mathrm{W}$. (a) Percentage contribution to the NEUC by water parcels originating from the different sections depicted in Figure $6 b$ as a function of integration time. (b-d) Illustration of the major pathways by displaying typical trajectories of the respective ensembles. The NEUC pathways reveal multiple recirculations of the trajectories between the EUC and the SEC bands before joining the eastward NEUC. no direct nonrecirculating connection between the NEUC and the western boundary is also revealed.

as above in Figures 7 and 8. For the NEUC the results after 4 years of integration are quite different than the actual pathways calculated with the daily velocity fields: after the 4 years of backtracking around $50 \%$ of the trajectories now originate from south of $6^{\circ} \mathrm{S}$ (compared to $31 \%$ with daily fields), the recirculation part has decreased to $42 \%$ (compared to $66 \%$ with daily fields). Thus the recirculation intensity for the northern hemisphere appears at least partially tied to the strength of the instability processes in this region. Figure $9 \mathrm{a}$ also suggests that the NEUC would be directly fed by the NBC only if there were no instability processes causing the recirculation pathway.

[40] For the southern hemisphere the difference between the trajectory calculations with and without waves appears less clear, especially regarding the partition between recirculation trajectories and the ones originating from south of $6^{\circ} \mathrm{S}$ which does not change between these runs. However, the fraction of trajectories connecting to the EUC is decreased by half in the runs with monthly mean velocity fields (44\% with daily fields, only $28 \%$ with monthly fields). Hence, the instability mechanisms also appear instrumental for the exchanges between the southern hemispheric current bands.
[41] A summary conclusion of the trajectory calculations thus is that the strong eddy variability, i.e., the prominent TIVs exhibited in Figure 5 exert a strong influence on the water mass pathways into the OEUCs by causing a zig-zag supply through different zonal current bands instead of a direct supply from the western boundary current. Thus, the residence time of water particles in this region is heavily elongated. While for the NEUC a very small fraction originates directly from the NBC, the SEUC is supplied entirely by the indirect pathway only.

\subsection{Upwelling and Fate of the NEUC}

[42] The depiction of the doming regions in Figure 1c revealed a good representation of the Guinea Dome but an absence of a circular doming on the southern hemisphere. The doming pattern is remarkably similar to the results of the study by Doi et al. [2007] but could also be attributed to or blurred by the southern model boundary within this region. Hence, in this chapter only the connections of the NEUC to the eastern upwelling will be studied. Here we use trajectories calculated forward in time, for particles starting in the NEUC at $23^{\circ} \mathrm{W}$. Typical trajectories and the upwelling sites of the water parcels after 4 years of integration are 

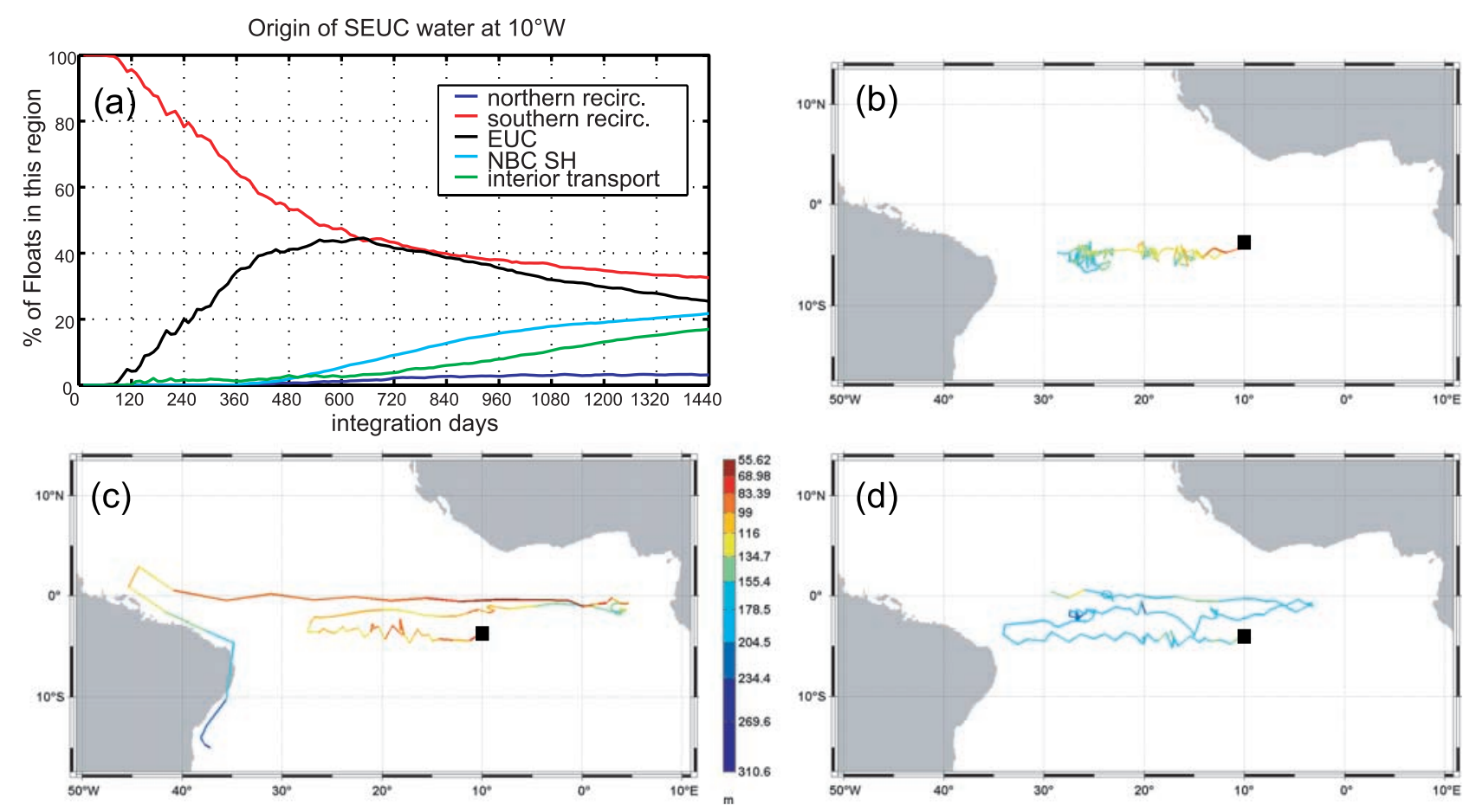

Figure 8. Contributions to the SEUC by different source pathways, based on backward integration of particles launched at $10^{\circ} \mathrm{W}$. (a) Percentage contribution to the SEUC by water parcels originating from the different sections depicted in Figure $6 \mathrm{~b}$ as a function of integration time. $(b-d)$ Illustration of the major pathways by displaying typical trajectories of the respective ensembles. Very similar to the source waters of the NEUC, the SEUC pathways are dominated by recirculation patterns between the different zonal current bands. In contrast to the NEUC, the SEUC is not supplied from the western boundary and is sustained by the interior ocean pathway only.

given in Figure 10. Upwelling is defined as the entrance of a particle into the surface layer across a depth of $30 \mathrm{~m}$.

[43] The upwelling pattern highlights two core regions: one along the equator and a second along the northwestern African coast reaching as far north as $20^{\circ} \mathrm{N}$. However, only a part of the trajectories $(32.1 \%$ of the mean NEUC transport) starting from the NEUC contribute to upwelling within the 4-year time span of integration, the remainder keeps recirculating below the surface. More than half of the upwelling occurs along the EUC $(19.5 \%$ of the mean NEUC transport) while only $12.6 \%$ of the NEUC reach the upwelling regions north of $3^{\circ} \mathrm{N}$ along the African coast and in the Guinea Dome. The pathways shown by the trajectories in Figures $10 \mathrm{~b}$ and $10 \mathrm{~d}$ imply that recirculation in the inner
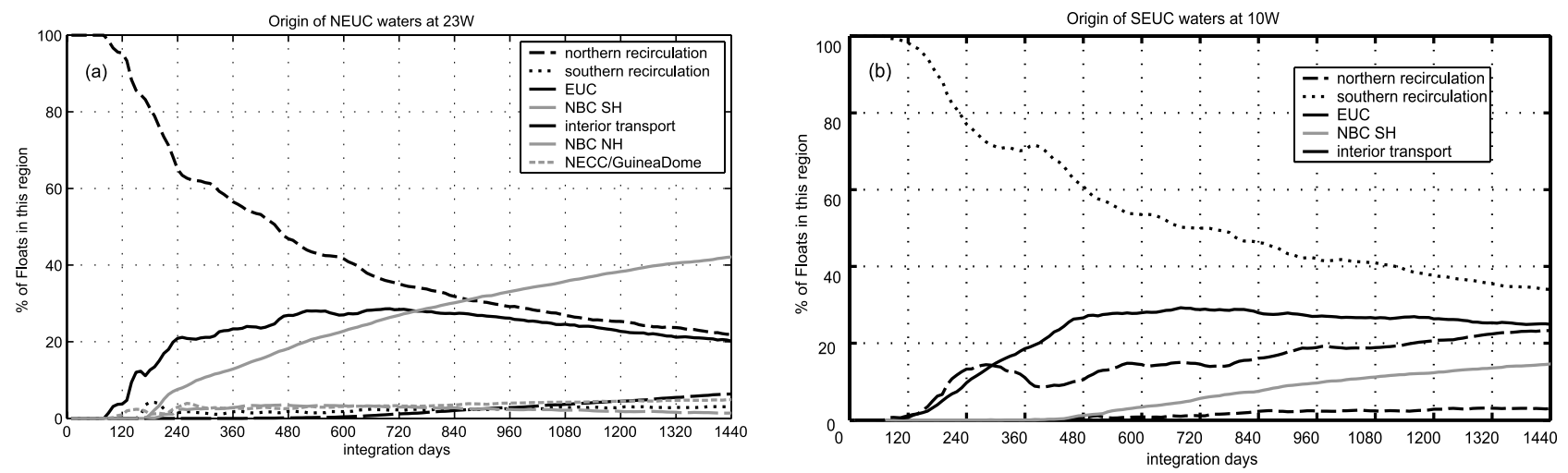

Figure 9. Sources of the (a) NEUC and (b) SEUC water masses calculated from monthly mean velocity fields and thus a strongly damped TIW activity. In comparison to the actual pathways in the eddying flow field (Figures 7 and $8 \mathrm{~b}$ ), the pathways in the smoothed flow fields where TIW activity is effectively damped out, involve a significant enhanced direct inflow to the NEUC from the western boundary current. The supply of the SEUC via the EUC is significantly weakened corresponding to the weaker eddy transports and thus reduced efficiency of the interior exchange path. 

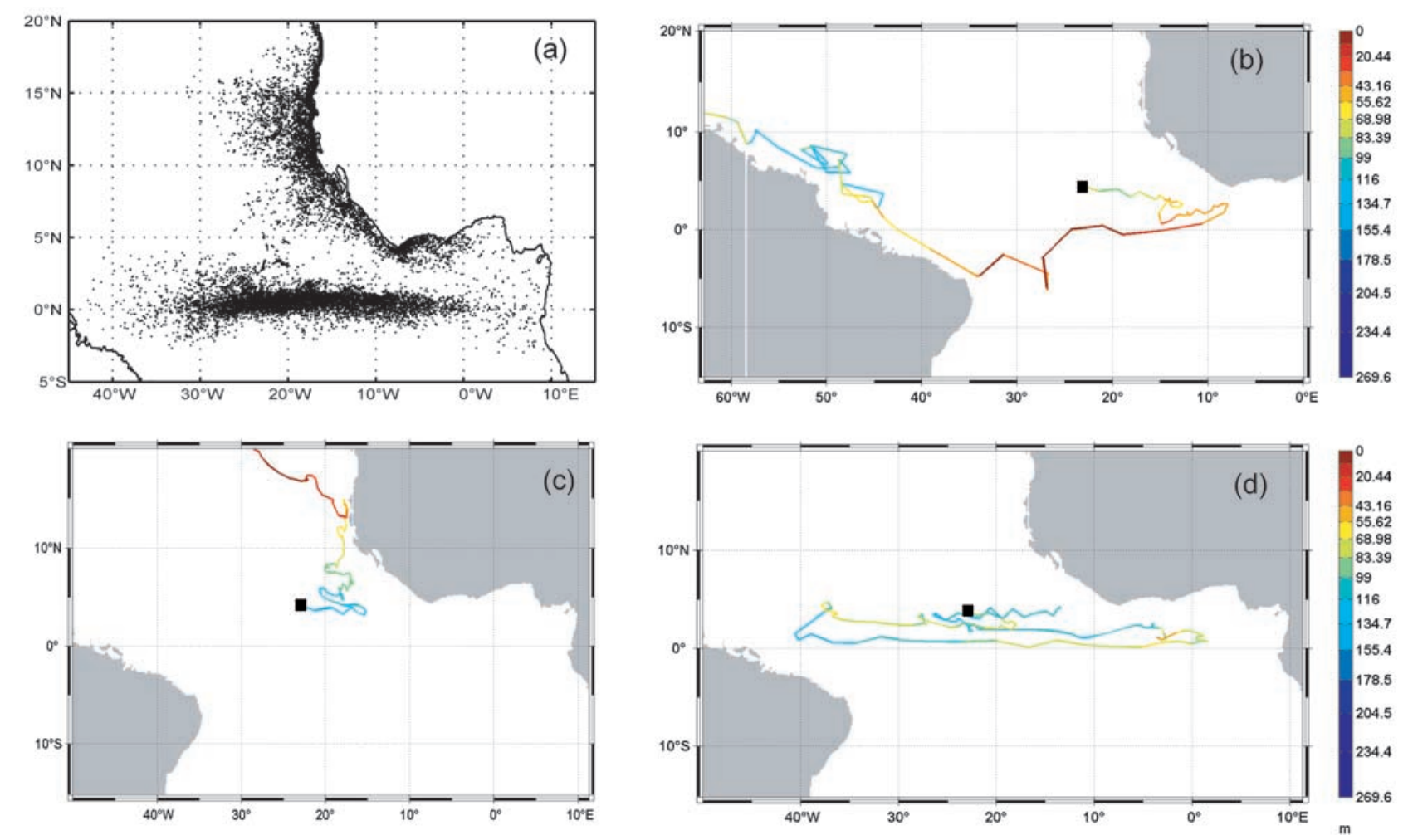

Figure 10. (a) Fate of the NEUC water masses in relation to eastern upwelling. Upwelling sites are defined by the entrance of a particle trajectory into the upper $30 \mathrm{~m}$. However, only $32 \%$ of the NEUC waters crossing the $23^{\circ} \mathrm{W}$ section take part in the upwelling during the 4 years of integration. The two main upwelling sites are along the equator and the African coast. Only few particles make their way toward the Guinea Dome and contribute to the upwelling there. (b-d) Exemplary pathways associated with the transport fractions. All trajectories show multiple zonal excursions and highlight the fact that most waters from the NEUC recirculate in the inner tropics.

tropics is the main reason for the low NEUC contribution to the upwelling. Both trajectories indicate similar pathways as found for the sources of the NEUC and underline the idea that a high fraction of water recirculates for more than 4 years in the inner tropics. Analogous experiments with monthly averaged velocity fields result in decreased upwelling rates in both the equatorial and the upwelling north of $3^{\circ} \mathrm{N}$, resulting from the decrease in the intensity of the instability processes.

[44] Figure 10c gives an example for a trajectory reaching the eastern boundary off the equator: after several zonal excursions the path finally ends up near the African coast and continues northward at the surface. The rather direct inflow from the NEUC into the Guinea Dome as suggested by the earlier works of Voituriez [1981] and Tsuchiya [1986] cannot be recognized, as the connection to the doming region is only realized as part of a much more complicated recirculation pattern through the different equatorial zonal currents. Similar supply pathways have been proposed by the study of Stramma et al. [2005], who suggested a similar pathway as given by the trajectory in Figure 10c to be the main source pathway for the Guinea Dome upwelling waters.

\section{Summary and Discussion}

[45] In this study a high-resolution ocean model was used to investigate the sources and fate of the off-equatorial undercurrents (OEUCs) in the tropical Atlantic Ocean. Eulerian analysis of the space-time structures of the equatorial current fields highlighted the dominant role of seasonal and higher-frequency variability in this regime. In contrast to most studies describing the equatorial currents separately from each other, the Lagrangian analysis presented here indicate a strong impact on equatorial pathways by interaction between the different eastward and westward current bands due to TIW-induced eddy processes. A feature not detectable in the present model analysis concerns the proposed poleward divergence of the OEUCs on their way eastward. However, the model indicates that the poleward shift of the undercurrents noted in observations by Bourlés et al. [2002] might also be related to the waveinduced meandering of the undercurrents.

[46] The analysis of the seasonal Eulerian flow fields revealed an interesting new aspect of the flow toward the OEUCs: throughout its seasonal cycle the SEUC did not show any direct linkage to the western boundary flow along the NBC. There have been speculations about such a connection by Arhan et al. [1998] and Mercier et al. [2003] because of the relative oxygen maximum of the SEUC waters, however, these ideas cannot be proved in this study. The model analysis instead suggests the SEUC to be connected year-round to a recirculation from the SEC band between the SEUC and the EUC. For the NEUC a similar connection to the northern SEC exists, but during fall and 
winter the flow fields suggest a clear linkage to the NBC retroflection. Further clarification of water mass pathways in this vigorously fluctuating current regime was obtained by analysis of Lagrangian particle trajectories. The particle trajectories revealed a dominance of indirect pathways into the SEUC, especially a connection to the EUC through the presence of tropical instabilities. These were found to significantly influence the spreading of southern hemisphere water masses by creating vortices (TIVs) in the mid and western basin of the tropical Atlantic, which effectively shift waters between adjacent zonal current bands. Similar behavior has been noted for trajectories of various APEX floats [Stramma et al., 2004].

[47] In contrast to the SEUC the NEUC revealed a direct inflow from the western boundary, although the eddyinduced recirculation pathway is the dominant source of the NEUC waters. Both OEUCs were shown to consist of major fractions of recirculating tropical water originating from the EUC and subsequently oscillating between the different zonal currents before entering the NEUC or SEUC. These recirculations occur mainly between the equator and about $4^{\circ} \mathrm{N} / \mathrm{S}$. Particles north or south of these latitudes usually do not recirculate back to the equator. Thus, the near-surface paths of the waters may be understood in terms of the "tropical cell" [Lu et al., 1998]. Although not ventilating the equatorial thermocline [Hazeleger et al., 2001, 2003], the TCs bear on the supply of the offequatorial currents, according to the Lagrangian analysis used here. Similar eddy-driven transport pathways have been previously described for nutrients and oxygen-rich waters by Menkes et al. [2002] in the context of ecosystem variability. Several other authors [see Foltz et al., 2004, and references therein] revealed a temperature advection associated with the instability waves. Additionally, the tropical instability waves have been proposed to be a key factor for the generation of the OEUCs [Jochum et al., 2004a]. However, there are several other papers showing that more mechanisms, e.g., off-equatorial upwelling [Furue et al., 2007], are needed to simulate the OEUCs realistically.

[48] In addition to their effect on the pathways of the OEUCs the multiple wave-induced recirculations in the tropical current system give an idea why the direct contributions of the NEUC and SEUC to the off-equatorial upwelling areas is that low. In the present model none of mean the currents connects directly to the upwelling regions of the doming circulations and the eastward pathways are blurred by the eddy-induced recirculation. According to the trajectory analysis only $12.6 \%$ (after 4 integration years) of the total eastward NEUC transport at $23^{\circ} \mathrm{W}$ reach the upwelling regions north of $3^{\circ} \mathrm{N}$, while a somewhat larger fraction of NEUC waters $(19.5 \%)$ contributes to the equatorial upwelling. There are no simple pathways standing out in the NEUC supply to the eastern basin, all trajectories show several zonal excursions, most of the NEUC trajectories $(67.9 \%)$ revealed recirculation pathways in the tropics. For the supply of the Guinea Dome a second pathway established by the seasonally occurring northern branch of the NECC [Richardson and Reverdin, 1987] was found to be important. As discussed by Stramma et al. [2005], this branch can also be related to tropical instability processes. Accordingly, the model indicates that by transferring mass from the NEUC to this northern NECC branch, the instability waves could be a key factor for the water mass pathway into the Guinea Dome region.

[49] A puzzling feature of the model concerns the magnitude of the off-equatorial upwelling. An investigation of the model's upwelling in the Guinea Dome region indicates weaker upwelling $(1.49 \mathrm{~Sv})$ than the Ekman divergence (4.4 Sv [see Schott et al., 2004]), based on the NCEP/ NCAR reanalysis fields. The difference might be related to the fact that the Ekman divergence is also supplied by the surface and upper layer currents or to a possibly unrealistic partition between NEUC waters transported to the EUC and along the African coast. The reasons for possible model biases in this regard have to be elucidated yet. Here we note, that additional experiments with a slightly different configuration of the FLAME model using an alternative mixed layer scheme (TKE) indicate only a weak dependence of the upwelling volume on the parameterization of turbulent mixing (M. Glessmer, personal communication, 2007) and confirm strong recirculations and blurred pathways of the OEUCs in the tropical Atlantic.

[50] Acknowledgments. This research was funded by the Bundesministerium fuer Bildung und Forschung (BMBF) as part of the NORDATLANTIK program (03F0443B). We acknowledge the contributions of the Kiel FLAME group to the development and integrations of the model experiment used in this analysis. A significant part of the model development was accomplished as part of the SFB 460, funded by the Deutsche Forschungsgemeinschaft (DFG). The experiments have been performed using the facilities and services of the Deutsches Klimarechenzentrum (DKRZ), Hamburg. Mirjam Glessmer is thanked for providing results of a trajectory analysis in a different FLAME configuration.

\section{References}

Arhan, M., H. Mercier, B. Bourles, and Y. Gouriou (1998), Hydrographic sections across the Atlantic at 7.30n and 4.30s, Deep Sea Res., 45(6), $829-872$.

Barnier, B., L. Siefridt, and P. Marchesiello (1995), Thermal forcing for a global ocean circulation model using a three-year climatology of ECMWF analysis, J. Mar. Syst., 6, 363-380, doi:10.1016/09247963(94)00034-9.

Blanke, B., M. Arhan, G. Madec, and S. Roche (1999), Warm water pathways in the equatorial Atlantic as diagnosed with a general circulation model, J. Phys. Oceanogr., 29, 2753-2768.

Böning, C. W., and J. Kröger (2005), Seasonal variability of deep currents in the equatorial Atlantic: a model study, Deep Sea Res., 52(1), 99-121.

Bourlés, B., M. D’Orgeville, G. Eldin, Y. Gouriou, R. Chuchla, Y. DuPenhoat, and S. Arnault (2002), On the evolution of the thermocline and subthermocline eastward currents in the Equatorial Atlantic, Geophys. Res. Lett., 29(16), 1785, doi:10.1029/2002GL015098.

Boyer, T. P., and S. Levitus (1997), Objective analyses of temperature and salinity for the world ocean on a $1 / 4$ degree grid, technical report, NOAA Atlas NESDIS 11, U.S. Govt. Print. Off., Washington, D. C.

Brandt, P., and C. Eden (2005), Annual cycle and interannual variability of the mid-depth tropical Atlantic Ocean, Deep Sea Res., 52(2), 199-219.

Brandt, P., F. A. Schott, C. Provost, A. Kartavtseff, V. Hormann, B. Bourls, and J. Fischer (2006), Circulation in the central equatorial Atlantic: Mean and intraseasonal to seasonal variability, Geophys. Res. Lett., 33, L07609, doi:10.1029/2005GL025498.

Brauch, J. P., and R. Gerdes (2005), Response of the northern North Atlantic and Arctic oceans to a sudden change of the North Atlantic Oscillation, J. Geophys. Res., 110, C11018, doi:10.1029/2004JC002436.

Doi, T., T. Tozuka, H. Sasaki, Y. Masumoto, and T. Yamagata (2007), Seasonal and interannual variations of oceanic conditions in the Angola Dome, J. Phys. Oceanogr., 37(11), 2698-2713.

Eden, C., and J. Willebrand (2001), Mechanism of interannual to decadal variability of the North Atlantic circulation, J. Clim., 14, 2266-2280.

Elmoussaoui, A., M. Arhan, and A. M. Treguier (2005), Model-inferred upper ocean circulation in the eastern tropics of the North Atlantic, Deep Sea Res., 52, 1083-1120.

Foltz, G. R., J. A. Carton, and E. P. Chassignet (2004), Tropical instability vortices in the Atlantic Ocean, J. Geophys. Res., 109, C03029, doi:10.1029/2003JC001942. 
Fratantoni, D., W. E. Johns, T. L. Townsend, and H. E. Hurlburt (2000), Low-latitude circulation and mass transport pathways in a model of the tropical Atlantic Ocean, J. Phys. Oceanogr., 30(8), 1944-1966.

Furue, R., J. P. McCreary, Z. Yu, and D. Wang (2007), Dynamics of the southern Tsuchiya Jet, J. Phys. Oceanogr., 37(3), 531-553.

Getzlaff, K., C. W. Böning, and J. Dengg (2006), Lagrangian perspectives of deep water export from the subpolar North Atlantic, Geophys. Res. Lett., 33, L21S08, doi:10.1029/2006GL026470.

Grodsky, S. A., J. A. Carton, C. Provost, J. Servain, J. A. Lorenzzetti, and M. J. McPhaden (2005), Tropical instability waves at $0 \mathrm{~N}, 23 \mathrm{~W}$ in the Atlantic: A case study using Pilot Research Moored Array in the Tropical Atlantic (PIRATA) mooring data, J. Geophys. Res., 110, C08010, doi:10.1029/2005JC002941.

Hazeleger, W., P. de Vries, and G. J. van Oldenborgh (2001), Do tropical cells ventilate the Indo-Pacific equatorial thermocline?, Geophys. Res. Lett., 28, 1766-2763.

Hazeleger, W., P. de Vries, and Y. Friocourt (2003), Sources of the equatorial undercurrent in the Atlantic in a high resolution ocean model, J. Phys. Oceanogr., 33, 677-693.

Hormann, V., and P. Brandt (2007), Atlantic Equatorial Undercurrent and associated cold tongue variability, J. Geophys. Res., 112, C06017, doi:10.1029/2006JC003931

Hua, B. L., F. Marin, and R. Schopp (2003), Three-dimensional dynamics of the subsurface countercurrents and equatorial thermostad. Part I: Formulation of the problem and generic properties, J. Phys. Oceanogr., 33 , 2588-2609.

Jochum, M., and P. Malanotte-Rizzoli (2001), Influence of the meridional overturning circulation on tropical-subtropical pathways, J. Phys. Oceanogr., 31(5), 1313-1323.

Jochum, M., P. Malanotte-Rizzoli, and A. Busalacchi (2004a), Tropical instability waves in the Atlantic Ocean, Ocean Modell., 7, 146-163.

Jochum, M., P. Malanotte-Rizzoli, and A. Busalacchi (2004b), A new theory for the generation of the equatorial subsurface undercurrents, J. Phys. Oceanogr., 34, 755-771

Johnson, G. C., and M. McPhaden (1999), Interior pycnocline flow from the subtropical to the Equatorial Pacific Ocean, J. Phys. Oceanogr., 29, 3073-3089.

Johnson, G. C., and D. W. Moore (1997), The Pacific subsurface countercurrents and an inertial model, J. Phys. Oceanogr., 27(11), 2448-2459.

Kalnay, E., et al. (1996), The NCEP 40-year reanalysis project, Bull. Am. Meteorol. Soc., 77, 437-471.

Kraus, E. B., and J. S. Turner (1967), A one-dimensional model of the seasonal thermocline I. A laboratory experiment and its interpretation, Tellus, 19, 88-97.

Levitus, S., and T. P. Boyer (1994), World Ocean Atlas 1994, NOAA Atlas NESDIS, NOAA, Washington, D. C.

Lu, P., J. P. McCreary, and B. A. Klinger (1998), Meridional circulation cells and the source waters of the Pacific Equatorial Undercurrent, J. Phys. Oceanogr., 28(1), 62-84.

Marin, F., B. L. Hua, and S. Wacongne (2000), The equatorial thermostad and subsurface countercurrents in the light of the dynamics of atmospheric Hadley cells, J. Mar. Res., 58(3), 405-437.

Marin, F., F. Schopp, and B. L. Hua (2003), Three-dimensional dynamics of the subsurface countercurrents and equatorial thermostad. part ii: Influence of the large-scale ventilation and equatorial winds, J. Phys. Oceanogr., 33, 2610-2626.

McCreary, J. P. (1981), A linear stratified ocean model of the Equatorial Undercurrent, Phil. Trans. Roy. Soc. London, Ser. A, 298, 603-635.

McCreary, J. P., and P. Lu (1994), Interaction between the subtropical and equatorial ocean circulations: The subtropical cell, J. Phys. Oceanogr. 24(2), 466-497.
McCreary, J. P., P. Lu, and Z. Yu (2002), Dynamics of the Pacific subsurface countercurrents, J. Phys. Oceanogr., 32, 2379-2404.

McPhaden, M. J. (1984), On the dynamics of equatorial subsurface countercurrents, J. Phys. Oceanogr., 14, 1216-1225.

Menkes, C. E., et al. (2002), A whirling ecosystem in the equatorial Atlantic, Geophys. Res. Lett., 29(11), 1553, doi:10.1029/2001GL014576.

Mercier, H., M. Arhan, and J. Lutjeharms (2003), Upper layer circulation in the eastern equatorial and South Atlantic oceans in January-March 1995, Deep Sea Res., 50, 863-887.

Metcalf, W., and M. C. Stalcup (1967), Origin of the Atlantic Equatorial Undercurrent, J. Geophys. Res., 72(20), 4959-4975.

Pacanowski, R. C. (1995), MOM 2 documentation, user's guide and reference manual, Tech. Rep. 3, Ocean Group, Geophys. Fluid Dyn. Lab. Princeton, N. J.

Philander, S. G. H., and R. C. Pacanowski (1986), A model of the seasonal cycle in the tropical Atlantic Ocean, J. Geophys. Res., 91(C12), 14,19214,206 .

Qiao, L., and R. H. Weisberg (1998), Tropical instability wave dynamics: observations from the Tropical Instability Wave Experiment, J. Phys. Oceanogr., 28(2), 345-360.

Richardson, P. L., and G. Reverdin (1987), Seasonal cycle of velocity in the Atlantic North Equatorial Countercurrent as measured by surface drifters, current meteres and ship drifts, J. Geophys. Res., 92, 3691-3708.

Rowe, G. D., E. Firing, and G. C. Johnson (2000), Pacific equatorial subsurface countercurrent velocity, transport and potential vorticity, J. Phys. Oceanogr., 30, 1172-1187.

Schott, F. A., J. P. McCreary, and G. Johnson (2004), Shallow overturning circulations of the tropical-subtropical oceans, in Earth's Climate: The Ocean-Atmosphere Interaction, Geophys. Monogr. Ser., vol. 147, pp. 261-304, AGU, Washington, D. C.

Schott, F. A., M. Dengler, R. J. Zantopp, L. Stramma, J. Fischer, and P. Brandt (2005), The shallow and deep western boundary circulation of the South Atlantic at $5^{\circ}-11^{\circ} \mathrm{S}, \mathrm{J}$. Phys. Oceanogr., 35, 2031-2053.

Stramma, L., J. Fischer, P. Brandt, and F. Schott (2004), Circulation, variability and near-equatorial meridional flow in the central tropical Atlantic, in Interhemispheric Water Exchanges in the Atlantic Ocean, Elsevier Oceanogr. Ser, vol. 68, edited by G. J. Goni and P. MalanotteRizzoli, pp. 1-22, Elsevier, New York.

Stramma, L., S. Hüttl, and J. Schafstall (2005), Water masses and currents in the upper tropical northeast Atlantic off northwest Africa, J. Geophys. Res., 110, C12006, doi:10.1029/2005JC002939.

Thierry, V., A. M. Treguier, and H. Mercier (2004), Numerical study of the annual and semi-annual fluctuations in the deep equatorial Atlantic Ocean, Ocean Modell., 6, 1-30.

Tsuchiya, M. (1975), Subsurface countercurrents in eastern equatorial Pacific Ocean, J. Mar. Res., 33, 145-175.

Tsuchiya, M. (1986), Thermostads and circulation in the upper layer of the Atlantic Ocean, Prog. Oceanogr., 16, 235-267.

Voituriez, B. (1981), Northern and southern equatorial undercurrents and the formation of tropical thermal domes, Oceanol. Acta, 4(4), 497-506. Weidman, P. D., D. L. Mickler, B. Dayyani, and G. H. Born (1999), Analysis of Legeckis eddies in the near-equatorial Pacific, J. Geophys. Res., 104(C4), 7865-7887.

Weisberg, R., and T. Weingartner (1988), Instability waves in the equatorial Atlantic Ocean, J. Phys. Oceanogr., 18, 1641-1657.

C. W. Böning, Leibniz-Institut für Meereswissenschaften an der Universität Kiel, Düsternbrooker Weg 20, D-24105 Kiel, Germany.

S. Hüttl-Kabus, Institut für Umweltphysik, Universität Bremen, OttoHahn-Allee 1, D-28359 Bremen, Germany. (huettl@uni-bremen.de) 